\title{
XXV. The variation in the Electrical Resistance of bismuth, when cooled to the temperature of solid air
}

James Dewar M.A. LL.D. F.R.S. \& J. A. Fleming M.A. D.Sc. F.R.S.

To cite this article: James Dewar M.A. LL.D. F.R.S. \&J. A. Fleming M.A. D.Sc. F.R.S. (1895) XXV. The variation in the Electrical Resistance of bismuth, when cooled to the temperature of solid air , Philosophical Magazine Series 5, 40:244, 303-311, DOI: 10.1080/14786449508620774

To link to this article: http://dx.doi.org/10.1080/14786449508620774

曲 Published online: 08 May 2009.

Submit your article to this journal $\pi$

Џll Article views: 2

Q View related articles $₫$ 
XXV. The Variation in the Electrical Resistance of Bismuth, when cooled to the Temperature of Solid Air. By JAMES Dewar, M.A., LL.D., F.R.S., Professor of Chemistry in the Royal Institution, \&c., and J.A. Fleming, M.A., D).Se., F.R.S., Professor of Electrical Engineering in University College, London*.

\section{[Plate V.]}

T the course of investigations on the Electrical Resistance 1 of pure metals and alloys at low temperatures made during the years 1892 and 1893 , the resnlts of which were communicated to the Philosophical Magazinet, extensive examination was made by us of the variation in specific electrical resistance exhibited by most of the ordinary metals when cooled to temperatures approaching the absolute zero. In the course of this research the abnormal behaviour of bismuth with regard to its variation of specific resistance with temperature was noted, and in a further research on the Thermo-electric powers of metals and alloys at low temperatures, the results of which were communicated to the Philosophical Magazine recently $\ddagger$, it was noticed that the curves representing the thermo-electric power of bismuth, both for pure and for commercial specimens, presented a discontinuity at temperatures lying between about $-70^{\circ}$ and $-100^{\circ}$. We were therefore recently led to make a more careful examination of the variation of electrical resistance of bismuth when cooled down to the temperature of solid air, some of the results of which are of sufficient interest to communicate, altbough the investigation is still in progress, and much remains to be done to complete it. A sample of very pure bismuth was kindly prepared for us by $\mathrm{Mr}$. George Matthey, by the reduction of the oxide, an analysis of which showed very small traces of iron as the only impurity. This bismuth, which was the same as that used by us in our thermo-electric experiments, was pressed into wire by a steel press, two sizes of wire being' prepared, one having a diameter of about 0.067 centimetre, and the other a diameter of 0.049 centimetre. Lengths of these wires were mounted up in an appropriate form for taking the electrical resistance when measured

* Communicated by the Authors.

$\dagger$ Dewar and Fleming, Phil. Mag. 1892, 5th series, vol, xxxiv. p. 326, "On the Electrical Resistance of Pure Metals, Alloys, and Non-Metals at the Boiling-point of Oxygen;" also Phil. Mag. 1898, 5th series, vol. xxxvi. p. 271, "The Electrical Resistance of Metals and Alloys at Temperatures approaching Absolute Zero."

$\ddagger$ Dewar and Fleming, Phil. Mag. July 1895. "Thermo-Electric Powers of Metals and Alloys between the Temperatures of the BoilingPoint of Water and the Boiling-point of Liquid Air." 
in liquid or in solid air, or at any other temperature up to $+100^{\circ} \mathrm{C}$.

Amongst other specimens a wire was pressed from some commercial bismuth, supposed to be fairly pure, which will be distinguished by being called Griffin's Bismuth; the diameter of this last wire was about 066 centimetre. The diameters of these wires were earefully measured with a microscope-micrometer in about twenty different places, the lengths of the wires used being about 30 or 60 centimetres. The sample of pure bismuth prepared for us by Mr. George Matthey will be distinguished by speaking of it as Matthey's bismuth, the thicker of the two wires being called $A$ and the thinner $B$. The dimensions and mean diameters of the pressed wires, which were used just as they came from the press, were as follows:-

$\begin{array}{ccc}\text { Sample. } & \begin{array}{c}\text { Length. } \\ \text { centim. }\end{array} & \begin{array}{c}\text { Mean diameter. } \\ \text { centim. }\end{array} \\ \text { Matthey's Bismuth (Pure), A ... } & 61 \cdot 25 & 0 \cdot 06713 \\ \text { Matthey's Bismuth (Pure), B . .. } & 32 \cdot 70 & 0 \cdot 04926 \\ \text { Griffin's Bismuth ................ } & 52 \cdot 90 & 0.06625\end{array}$

In addition to these samples of pressed wires, other specimens were prepared by drawing melted bismuth up into fine glass tubes and making a suitable connexion with the bismuth for the purpose of an electrical resistance measurement by means of tinned copper wires melted in to the ends of the bismuth specimen. These samples of bismuth then had their electrical resistance measured with a Wheatstone bridge in the usual way, the temperature of the specimen being taken at the same time by means of a platinum thermometer, consisting of a platinum wire closely in contact with the specimen of bismuth. All the temperatures which are given in the following paragraphs have been converted into platinum temperatures, taken in terms of our standard platinam thermometer $\mathrm{P}_{1}$, the electrical constants of which were given by us in the paper on the Thermo-electric powers of metals (see Phil. Mag. July 1895). Temperatures so measured are distinguished by the letter $P_{1}$ placed after the number denoting the temperature. The electrical resistance of the bismuth specimens, all proper corrections being made for the resistance of the connecting wires, was taken at a large number of temperatures lying between the boiling-point of water $\left(100^{\circ} \mathrm{C}\right.$.) down to the temperature of solid air, which, in terms of our standard platinum thermometer $P_{1}$ is about $-233^{\circ} P_{1}$ to $-235^{\circ} P_{1}$. From the known dimensions of the bismuth wires the volume specific resistance of the metal was calculated at these different temperatures, and the reduced observations for the three specimens above mentioned are given in the following tables:- 
in the Electrical Resistance of Bismuth.

Commercial Bismuth (Griffin's).

\begin{tabular}{|c|c|c|c|}
\hline $\begin{array}{c}\text { Volume Specific } \\
\text { Resistance } \\
\text { in O.G.S. units. }\end{array}$ & $\begin{array}{c}\text { Temperature } \\
\text { in Platinum } \\
\text { degrees. }\end{array}$ & $\begin{array}{c}\text { Volume Specific } \\
\text { Resistance } \\
\text { in C.G.S. units. }\end{array}$ & $\begin{array}{c}\text { Temperature } \\
\text { in Platinum } \\
\text { degrees. }\end{array}$ \\
\hline $\begin{array}{l}190700 \\
186850 \\
180350 \\
176450 \\
176200 \\
175200 \\
173650 \\
172000 \\
172300 \\
171450 \\
171050 \\
171100 \\
17650 \\
172050 \\
173400 \\
173700 \\
176050 \\
176700 \\
179050 \\
180100 \\
184400\end{array}$ & $\begin{array}{l}+950 \\
+84.6 \\
+66.6 \\
+47.0 \\
+46.5 \\
+41 \cdot 2 \\
+340 \\
+21.3 \\
+18.8 \\
+5.2 \\
-2 \cdot 2 \\
-6 \cdot 8 \\
-25 \cdot 0 \\
-32.7 \\
-43.0 \\
-47 \cdot 3 \\
-59 \cdot 6 \\
-63.3 \\
-75 \cdot 1 \\
-79 \cdot 1 \\
-92.9\end{array}$ & $\begin{array}{l}185050 \\
188450 \\
190050 \\
193800 \\
195400 \\
199700 \\
200700 \\
205400 \\
207000 \\
211450 \\
211750 \\
212800 \\
212800 \\
212050 \\
212100 \\
211700 \\
211500 \\
210900 \\
209700 \\
208900 \\
208950\end{array}$ & $\begin{array}{l}\quad 96 \cdot 9 \\
-107 \cdot 9 \\
-111 \cdot 7 \\
-123 \cdot 5 \\
-128 \cdot 1 \\
-140 \cdot 0 \\
-143 \cdot 9 \\
-157 \cdot 0 \\
-162 \cdot 0 \\
-180 \cdot 0 \\
-184 \cdot 0 \\
-196 \cdot 6 \\
-196 \cdot 8 \\
-213 \cdot 2 \\
-215 \cdot 5 \\
-217 \cdot 1 \\
-220 \cdot 1 \\
-222 \cdot 5 \\
-228 \cdot 5 \\
-232 \cdot 8 \\
-233 \cdot 2\end{array}$ \\
\hline \multicolumn{4}{|c|}{ Pure Bismuth (A) (Matthey's). } \\
\hline $\begin{array}{l}\text { Volume Specific } \\
\text { Resistance } \\
\text { in C.G.S. units. }\end{array}$ & $\begin{array}{c}\text { Temperature } \\
\text { in Platinum } \\
\text { degrees. }\end{array}$ & $\begin{array}{l}\text { Volume Specific } \\
\text { Resistance } \\
\text { in C.G.S. units. }\end{array}$ & $\begin{array}{l}\text { Temperature } \\
\text { in Platinum } \\
\text { degrees. }\end{array}$ \\
\hline $\begin{array}{l}202550 \\
185100 \\
174200 \\
171100 \\
169750 \\
168150 \\
166900 \\
166550 \\
166300 \\
165850 \\
165600 \\
165400 \\
165050 \\
164800 \\
164750 \\
104750 \\
164900 \\
165500 \\
165850 \\
166150 \\
167300 \\
168600 \\
169400 \\
171100 \\
175150 \\
176950 \\
178950 \\
181150\end{array}$ & 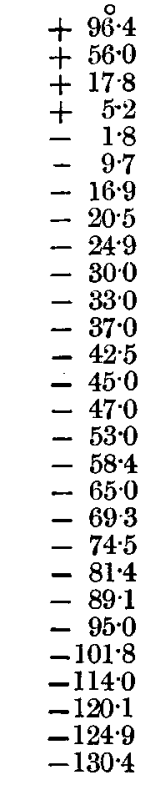 & $\begin{array}{l}183350 \\
186000 \\
188850 \\
193100 \\
197450 \\
200650 \\
204800 \\
208250 \\
211350 \\
213950 \\
217100 \\
220200 \\
222500 \\
225300 \\
228150 \\
229300 \\
229850 \\
231800 \\
242150 \\
248150 \\
264400 \\
266250 \\
267900 \\
276700 \\
288450 \\
293100 \\
294300 \\
294300\end{array}$ & $\begin{array}{l}-135 \cdot 0 \\
-139 \cdot 0 \\
-145 \cdot 9 \\
-151 \cdot 6 \\
-156 \cdot 6 \\
-160 \cdot 6 \\
-165 \cdot 8 \\
-170 \cdot 5 \\
-173 \cdot 9 \\
-176 \cdot 8 \\
-179 \cdot 8 \\
-183 \cdot 0 \\
-186 \cdot 3 \\
-188 \cdot 9 \\
-192 \cdot 0 \\
-192 \cdot 7 \\
-193 \cdot 3 \\
-197 \cdot 0 \\
-202 \cdot 6 \\
-207 \cdot 9 \\
-219 \cdot 3 \\
-220 \cdot 8 \\
-222 \cdot 0 \\
-227 \cdot 1 \\
-232 \cdot 0 \\
-234 \cdot 2 \\
-234 \cdot 85 \\
-234 \cdot 9\end{array}$ \\
\hline
\end{tabular}


Pure Bismuth (B) (Matthey's).

\begin{tabular}{|c|c|c|c|}
\hline $\begin{array}{c}\text { Volume Specific } \\
\text { Resiatance } \\
\text { in } 0 . G . \text {. . units. }\end{array}$ & $\begin{array}{c}\text { Temperature } \\
\text { in Platinum } \\
\text { degrees. }\end{array}$ & $\begin{array}{l}\text { Volume Specific } \\
\text { Resistance } \\
\text { in C.G.S. units }\end{array}$ & $\begin{array}{l}\text { Temperature } \\
\text { in Platinum } \\
\text { degrees. }\end{array}$ \\
\hline $\begin{array}{l}175100 \\
174850 \\
165100 \\
163050 \\
161550 \\
161250 \\
158400 \\
157900 \\
153750 \\
153300 \\
152350 \\
152050 \\
151000 \\
150850 \\
150500\end{array}$ & $\begin{array}{l}+49 \cdot 2 \\
+48 \cdot 0 \\
+18 \cdot 8 \\
+11 \cdot 3 \\
+3.6 \\
+1 \cdot 3 \\
-11 \cdot 5 \\
-18 \cdot 3 \\
-36.5 \\
-40.0 \\
-51.6 \\
-55 \cdot 3 \\
-66.8 \\
-71.0 \\
-83.3\end{array}$ & $\begin{array}{l}150600 \\
151300 \\
151300 \\
152000 \\
152850 \\
154950 \\
155900 \\
159450 \\
161200 \\
1650300 \\
169850 \\
179550 \\
181000 \\
181000\end{array}$ & $\begin{array}{r}0 \\
-87 \cdot 9 \\
-100 \cdot 5 \\
-103 \cdot 9 \\
-114 \cdot 8 \\
-118 \cdot 8 \\
-132 \cdot 2 \\
-136 \cdot 1 \\
-148 \cdot 1 \\
-152 \cdot 2 \\
-168 \cdot 0 \\
-174 \cdot 9 \\
-193 \cdot 4 \\
-196 \cdot 2 \\
-196 \cdot 8\end{array}$ \\
\hline
\end{tabular}

The above numerical results are set out in the form of three curves (see Plate V.). It will be seen that the specific electrical resistance of all the bismuth specimens taken from $100^{\circ} \mathrm{C}$. downwards gradually diminishes to a point which, in the case of the specimen of pure bismuth " $\mathrm{A}$ " was about $50^{\circ} \mathrm{P}_{1}$, and in the case of the specimen " $\mathrm{B}$ " about $-83^{\circ} \mathrm{P}_{1}$. After these temperatures had been reached,further cooling increased instead of diminishing the electrical resistance of the $\mathrm{A}$ and $\mathrm{B}$ bismuth, until, at the lowest temperature reached by the employment of large quantities of solid air, the electrical resistance of the specimen "A" had become increased by nearly 80 per cent. of its minimum resistance, and at the same time the mean temperature coefficient had become very large, and of course negative. It may be noted that the melting-point of solid air, as determined by our standard platinum thermometer, is $-232^{\circ} \cdot 2 \mathrm{P}_{1}$, liquefaction taking place under a pressure of 14 millim. of mercury. The boiling-point of liquid air under a pressure of 746 millim. is $-209^{\circ} .75 \mathrm{P}_{1}$. The same general facts were observed in the case of the specimen of pure bismuth " B," only in this instance the temperature was not taken below about $-200^{\circ} \mathrm{P}_{1}$. As regards the commercial bismuth (Griffin's) the curves show that after reaching a minimum point, which for that specimen appears to occur at about $0^{\circ} \mathrm{C}$., there is another point of inflexion in the resistance-curve in the neighbourhood of $-200^{\circ} P_{1}$, after which the resistance again diminishes. In the case of each 
Phit. Mas s. S 5 . Vol 40 P1. V

THE VARIATION OF ELECTRICAL RESISTANCE OF BISMUTH WITH TEMPERATURE.

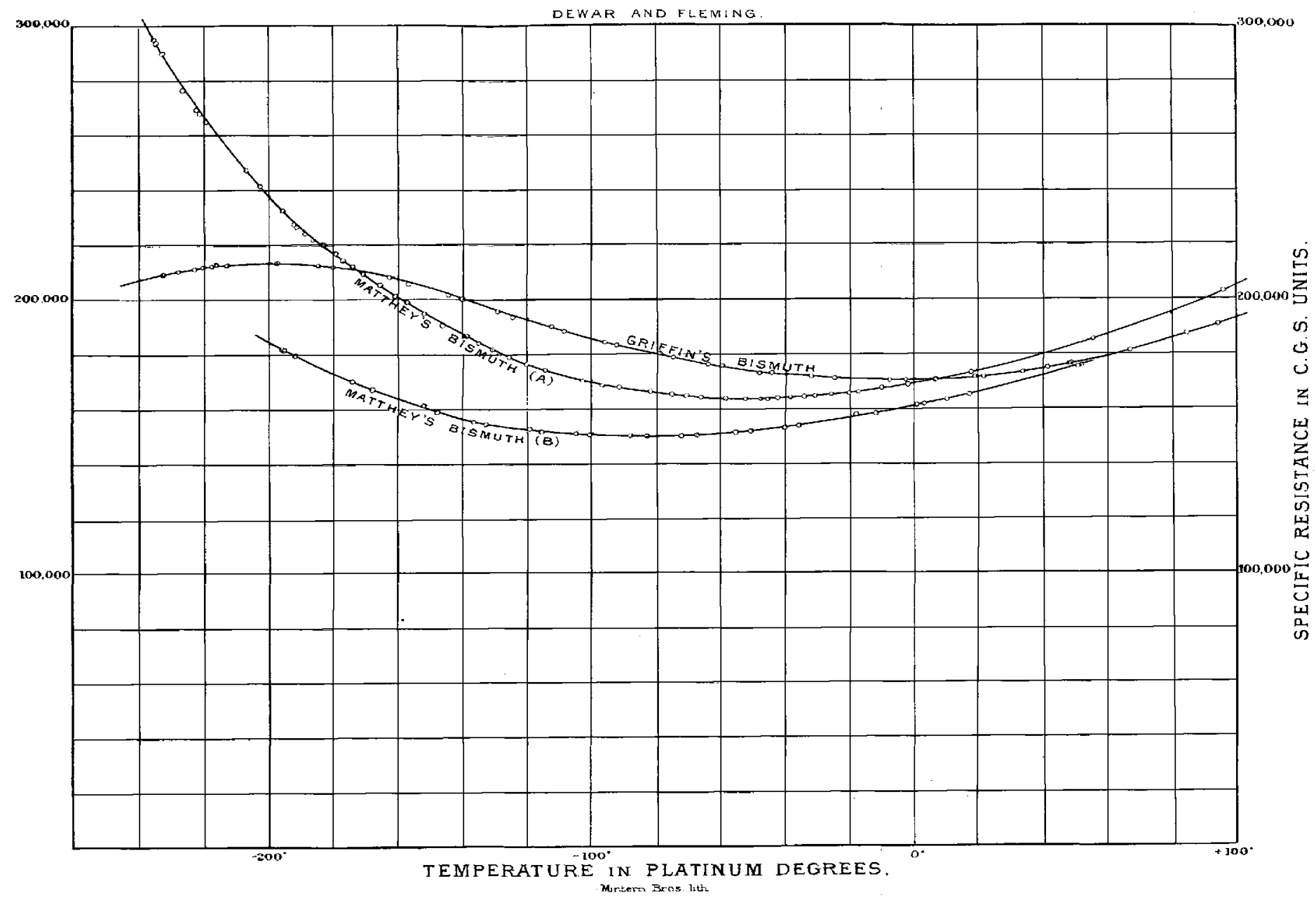


of these specimens the resistance measurements were repeated many times, and in both directions, to obtain an assurance that the relation of resistance and temperature was perfectly definite, and that proof might be obtained that all the three specimens of pressed bismuth wire as well as the bismuth melted in the tubes, did not undergo any permanent change in their condition by the action of the low temperature, but that there was a definite relation between temperature and electrical resistance in the manner shown in the curves. Similur experiments made with pure antimony drawn up into glass tubes did not show the appearance of any minimum resistance for any temperature between $0^{\circ}$ and $-200^{\circ} \mathrm{P}_{1}$. In no other case amongst all the metals and alloys examined by us has any phenomenon presented itself similar to that shown by the above specimens of pure bismuth. So far, therefore, as these investigations have gone they show that the behaviour of bismuth at low temperatures in respect of electrical conductivity is anomalous. The temperature-resistance curves of these specimens are quite different to those of other pure metals. In our first communication on the electrical resistance of metals (see Phil. Mag. October, 1892) we showed that carbon taken in the form of a carbon filament from an incandescent lamp increases its resistance continuously when cooled down to the boiling-point of oxygen, and we suggested that for pure non-metals continual lowering of the temperature towards the absolute zero would in all probability continually increase the specific electrical resistance. In the specimens of pure bismuth $A$ and $B$ there is no indication at the luwest temperature reached, viz. $-235^{\circ} \mathrm{P}_{1}$, that the resistance lines for this pure bismuth would have another point of inflexion. If, then, the specific resistance of these samples of pure bisnuth goes on increasing continuously down to the absolute zero of temperature, as it would appear to do, in that respect they behave like a non-metal, having, however, a very much larger temperature coefficient than carbon. The behaviour of bismuth in a magnetic field in regard to electrical resistance, and also the fact that different specimens of bismuth have in some cases positive and in other cases negative temperature coefficients at tem. peratures above $0^{\circ} \mathrm{C}$., has been examined by other observers. Without entering into any historical statement of the course of investigation in this matter, brief reference may be made to two papers on this subject which have a bearing on the facts here described by us. In 1886 an experimental study of the infiuence of magnetism and temperature on the electrical resistance of bismuth, and also of its alloys with 
lead and tin, was described by M. von Aubel (see Phil. Mag. 1888, 5th series, vol. xxv. p. 191). He studied the electrical resistance of certain specimens of pure bismuth in the form of rods slowly cooled, and for temperatures between $17^{\circ} \cdot 2 \mathrm{C}$. and $70^{\circ} .8 \mathrm{C}$. found a negative coefficient for some of these specimens. In the case of rods of pure bismuth which had been tempered between temperatures $15^{\circ} \cdot 2 \mathrm{C}$. and $69^{\circ} \cdot 7 \mathrm{C}$. he found a positive temperature coefficient within these limits; that is to say, in the first case heating the bismuth decreased its resistance, and in the second case heating the bismuth increased its resistance between the stated limits of temperature. In none of the samples of bismuth examined by us have we found a negative temperature coefficient for temperatures above $0^{\circ} \mathrm{C}$.

For a certain specimen of compressed bismuth wire M. von Aubel found the resistance practically constant between $16^{\circ} .8 \mathrm{C}$. and $76^{\circ}$ C.; but on melting, cooling, and annealing the same specimen it acquired a positive temperature coefficient between these limits. M. von Aubel examined the electrical resistance of certain bismuth-lead-tin alloys, and he came to the conclusion that the cause of these anomalies in the temperature coefficient of bismuth was the varying physical condition of the bismuth, and not the presence of impurities. In $1894 \mathrm{Mr}$. J. B. Henderson published a paper "On the Effects of Magnetic Fields on the Electric Conductivity of Bismuth" (see Phil. Mag. 1894, 5th series, p. 488), and he gives a series of curres showing the temperature variation of bismuth when taken in magnetic fields of different strengths. For a certain specimen of bismuth wire, and for a certain magnetic field-strength of about 10,000 C.G.S. units, his curves indicate a point of minimum resistance for the bismuth. Taking the bismuth at a certain temperature, the temperature coefficient at that point in a zero magnetic field was found to be positive; but on gradually increasing the strength of the magnetic field in which the hismuth was immersed the temperature coefficient finally became negative. One point of interest, then, in connexion with these investigations is whether the specific resistance of bismuth always presents a minimum value, and whether the temperature at which this minimum valne occurs depends upon the strength of the magnetic field in which the bismuth is immersed as well as upon the physical condition of the metal. In the case of the two wires of pure bismnth " $A$ " and " $B$ ' used by us, the diameters of the wires were different, and the pressures under which they were formed, and therefore the physical condition in the interior of the 
wire, was no doubt also different. Hence although both these wires present a point of minimum electrical resistance, the temperature at which this occurs is not identically the same. Another point of interest is that the temperature at which a discontinuity was found by us in the thermo-electric line of the pure bismuth, and which was found to be about $-80^{\circ} \mathrm{C}$., is also approximately the point at which the resistance-temperature coefficient of the same bismuth becomes sensibly negative. It is therefore clear that at this temperature a critical point is reached for this particular sample of bismuth, and below this point the bismuth undergoes a physical change which affects its thermo-electric value as well as its resistancetemperature coefficient. These investigations indicate that the electrical behaviour of bismuth in certain states at and below particular temperatures is irregular, and that further study is necessary to arrive at a complete explanation of the facts. It has been pointed out by one of us (see Friday Evening Discourse at the Royal Institution, by Professor Dewar, "On the Scientific Uses of Liquid Air," Jan. 19, 1894) that the tensile strength of very many metals is greatly increased by cooling them down to the temperature of liquid oxygen, but that there is a very marked decrease in the tensile strength of bismuth as well as of antimony and some other metals when taken down to the same low temperature. It is interesting to note that bismuth, which, at any rate in certain states, presents the anomaly of a discontinuity in its curve of thermo-electromotive force at a certain low temperature, has also at about the same temperature a change of sign of the temperature coefficient, and becomes in addition exceedingly brittle below that temperature.

In an interesting paper on the Mechanism of Electrical Conduction (see Yhil. Mag. ser. 5, 1894, vol. xxxviii. p. 57) Dr. C. V. Burton makes reference to our former experiments on the resistance of pure metals, and states and proves a theorem to the effect that at the absolute zero of temperature every substance must have either infinite specific resistance or infinite conductivity. In the samples of bismuth $A$ and $B$ we have before us a material which exhibits, as far as we can judge, a tendency in its specific resistance to continually increase as it is cooled to temperatures lying below about $-80^{\circ}$. In this respect it resembles a non-metal, and the question arises whether this is the proper characteristic behaviour of pure bismuth, or whether in any other physical condition it would show the normal quality of pure metals in decreasing its specific resistance regularly as it is cooled towards the absolute zero. 


\section{The Variation in the Electrical Resistance of Bismuth.}

With the object of ascertaining this we have also tested some very pure bismuth kindly sent to us by Mr. Edward Matthey, and which was prepared by the reduction of the oxychloride. This being pressed into wire was found to give a resistance-temperature curve very similar in general form to that marked Griffin's Bismuth in Plate V. The resistance decreased down to about $0^{\circ} \mathrm{C}$., and then increased again when cooled to about $-160^{\circ}$, and finally decreased again. It is clear, therefore, that the specimens of bismuth, viz. that prepared for us by Mr. George Matthey from the oxide and that prepared by Mr. Edward Matthey from the oxychloride, and which are both very pure, behave quite differently at very low temperatures with regard to their electrical conductivity. We have also examined the variation of a sample of bismuth prepared electrolytically, but the result of this examination we reserve until the observations have been confirmed on other samples of electrolytic bismuth. One fact of considerable interest has presented itself in studying the action of a magnetic field on the electrical resistance of bismuth cooled to low temperatures. It is well known that the electrical resistance of bismuth is increased by being immersed in a magnetic field. Taking a sample of the pure (Matthey) bismuth wire, we measured its electrical resistance at $18^{\circ} \mathrm{C}$. in the earth's field and when placed transversely in the field of an electromagnet, and found an increase of resistance due to the field in the ratio of 1.361 to 1.434 , or about 5 per cent. The same sample was cooled in liquid oxygen, and metsured again in the same fields. The resistances were then in the ratio of 1.478 to 1.858 . The increase in resistance in this last case is nearly 25 per cent. Hence the cooling of the bismuth to $-182^{\circ} \mathrm{C}$. increased the effect of a given magnetic field in altering its resistance about five times.

Another experiment was made to ascertain whether increased pressure on the surface of the bismuth affected its resistance. When a sample of pure bismuth wire was subjected to an external surface-pressure of 300 atmospheres, a very slight but definite increase of resistance was found, which disappeared instantly on removing the pressure.

The above described observations show that there is a very marked difference between different samples of bismuth as regards electrical resistance when subjected to very low temperatures, and that its behaviour at these temperatures in magnetic fields is also abnormal. We propose to reserve further remarks on this subject until we have completed the 
experiments in progress on electrolytic bismuth. We expect then to be able to state the results obtained for specimens of bismuth of known chemical purity, and to distinguish between those effects which are due to physical condition and those, if any, arising from the presence of minute traces of impurity.

\section{XXVI, Notices respecting New Books.}

A Geological Inquiry respecting the Water-bearing Strata of the Country around London, with Reference especially to the Watersupply of the Metropolis; and including some Remarks on Springs. By Joseph Prestwich, $\boldsymbol{l}^{\prime}$.G.S. 8vo, ix \& 238 pages. Gurney and Jackson : Iondon, 1851-1895.

THIS useful work was first published in 1851, and is now re-issued, for reasons given in the Preface, with some additions, by the energetic author Dr. J. Prestwich, F.R.S., \&c. \&c., who has greatly enlarged his experience in this and other branches of (jeology during the long interval of forty years, occupied with active research, including the work of his Professorship in the University of Oxford. The large plate engraved in 1851 was accidentally destroyed before a sufficient number of copies were printed for the book; and the remainder of the work was put aside, and the plate not reproduced, because one of the sections of the plate (No. 1, from Sussex to Bedfordshire) was proved to be incorrect, the palæozoic: rocks having been discovered to be within reach under London. It was thought, too, that this error affected the long section (No. 2 from Wilts to Essex); but these old underlying rocks are really so much limited in area that the western portion of the district traversed by the section is properly represented in it; and the inference as to the possibility of a considerable supply of water being obtainable from the Lower Greensand there still holds good. For this reason the remainder of the printed matter of the book is now issued, without the plate, but with a few new pages (pp. $v$ to ix).

There is now proved to be a belt, variable in width, of watercarrying Lower Greensand encircling the area of underground palaozoic rocks, over which borings do not give so large a watersupply as the Lower Greensand can give. These sand beds extend under the Chalk and Tertiary strata and beyond their outcrop; thus receiving the necessary rainfall. Their exact yield of water, however, has not been yet ascertained. A certain amount bas been obtained by boring in the Lower Greensand, eastward of London, at Shoreham, Strood, Frindsbury, and Loughton. In the westeru division of the London Basin the recent boring at Wingfield, not far from Ascot, affords ample proof that there exists a large underground supply, as indicated by nearly 3000 gallons in the 24 hours, 